tasis is encountered, the lesion may be amenable to surgical resection. ${ }^{6}$ Fujii and colleagues ${ }^{6}$ have advocated the resection of solitary breast cancer metastases followed by chemotherapy when local control may be achieved, and when the disease-free interval has been long, indicative of a slow-growing primary tumor. Oka and associates ${ }^{7}$ reported on resection of a metastasis from a lung cancer primary after a latency period of 5 years; the patient remained without recurrence 23 months after resection. Mizobuchi and colleagues ${ }^{2}$ reported on 3 cases of esophagectomy, including the one previous patient with an ovarian cancer metastasis; longterm survivals of 4 and 14 years were achieved in patients in which the disease-free intervals had been 7 and 16 years, respectively.

In the case of our patient, the solitary esophageal metastasis was seen after a disease-free interval of approximately 4 years. Positron emission tomographic scan did not detect extrathoracic disease, and local control of the tumor appeared achievable. Because of the patient's age and relative health, resection followed by adjuvant therapy was pursued. The choice to perform resection before chemotherapy is consistent with the strategy to perform surgical debulking before systemic therapy for ovarian cancer; however, the use of preoperative chemotherapy followed by surgical resection would seem to be equally feasible. Although the ultimate prognosis of esophageal metastases is poor, effective symptom resolution and long-term disease-free interval are achievable goals for resection. Appropriate patients would include those in sufficiently good preoperative health with solitary metastasis from slow-growing tumors, as evidenced by a relatively long symptom-free interval. For effective resection with an acceptable level of morbidity, the transhiatal approach is advocated.

\section{References}

1. Asamura H, Goya T, Hirata K, Suemasu K, Itabashi M, Matsuno Y, et al. Esophageal and pulmonary metastases from ovarian carcinoma: a case report of long-term survival following metastatic resections. Jpn J Clin Oncol. 1991;21:211-7.

2. Mizobuchi S, Tachimori Y, Kato H, Watanabe H, Nakanishi Y, Ochiai A. Metastatic esophageal tumors from distant primary lesions: report of three esophagectomies and study of 1835 autopsy cases. Jpn J Clin Oncol. 1997;27:410-4.

3. Anderson MF, Harell GS. Secondary esophageal tumors. AJR Am J Roentgenol. 1980;135:1243-6.

4. Agha FP. Secondary neoplasms of the esophagus. Gastrointest Radiol. 1987; $12: 187-93$.

5. Dauplat J, Neville F, Hacker NF, Nieberg RK, Berek JS, Rose TP, et al. Distant metastases in epithelial ovarian carcinoma. Cancer. 1987;60: 1561-6.

6. Fujii K, Nakanishi Y, Ochiai A, Tsuda H, Yamaguchi H, Tachimori Y, et al. Solitary esophageal metastasis of breast cancer with 15 Years' latency: a case report and review of the literature. Pathol Int. 1997;47: 614-7.

7. Oka T, Ayabe H, Kawahara K, Tagawa Y, Hara S, Tsuji H, et al. Esophagectomy for metastatic carcinoma of the esophagus from lung cancer. Cancer. 1993;71:2958-61.

\title{
Massive pneumoencephalus of late onset after an en bloc resection for lung cancer
}

\author{
Marco Lucchi, MD, Paolo Dini, MD, Francesco Givigliano, MD, Alessandro Ribechini, MD, and Alfredo Mussi, MD, \\ Pisa, Italy
}

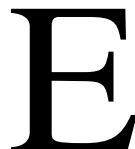

xtended resections are considered a valid therapeutic option in cases of selected locally advanced lung cancer in reason of an acceptable morbidity. ${ }^{1-3}$ Multimodality treatment, including chemotherapy, radiotherapy, and surgical intervention, has proved to improve the results in terms of disease-free and overall survival, ${ }^{4-6}$ despite a major postoperative morbidity. $^{7}$

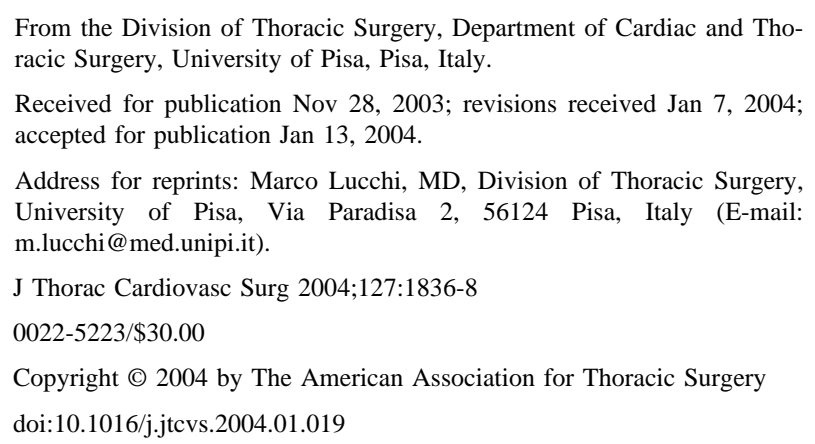

Pneumoencephalus is a rare complication of important cranial trauma $^{8}$ or neurosurgery, ${ }^{9}$ but to our knowledge, it was never reported after thoracic surgery. We report a case of massive pneumoencephalus appearing late after an en bloc upper right lobectomy for lung cancer in a patient who previously underwent chemoradiotherapy. Thoracic surgeons should be aware of this possible complication when an extended lung resection involving the ribs and the vertebral bodies is performed.

\section{Clinical Summary}

A 76-year-old man was referred for surgical treatment of right upper lobe squamous carcinoma infiltrating the chest wall. Previously, the patient underwent 3 cycles of neoadjuvant chemotherapy (carboplatin and paclitaxol) and radiotherapy (40 Gy) with a partial response $(<50 \%)$. At the operation, we performed an en bloc right upper lobectomy with the posterior arches of the first 4 ribs and the transverse process of D2.

The postoperative course was uneventful, and the patient was discharged on the ninth day. The pathologic examination showed 

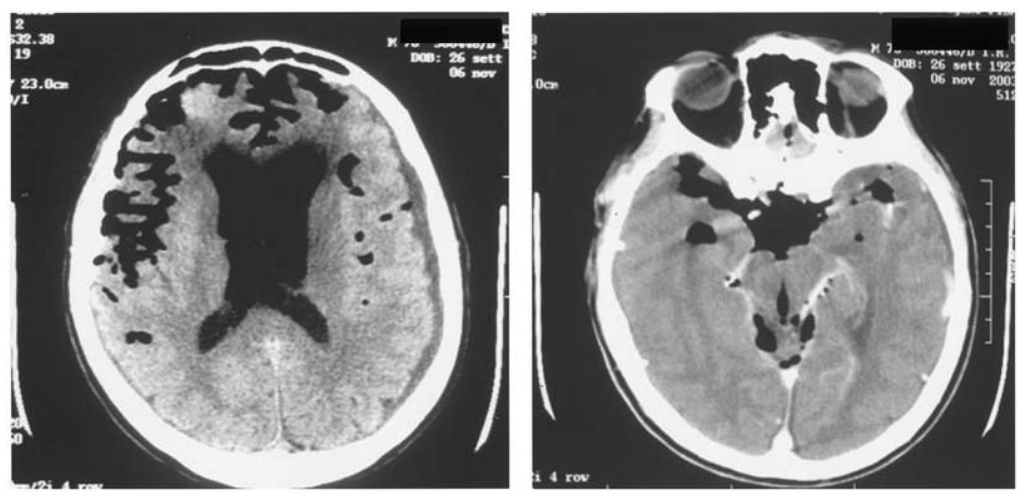

Figure 1. Brain computed tomographic scan showing the massive pneumoencephalus.
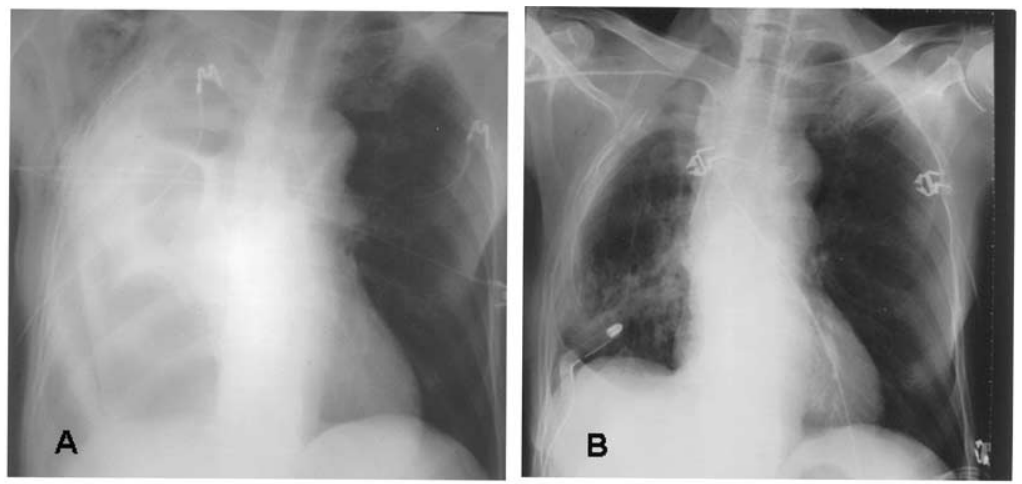

Figure 2. Chest radiographs with the right hydropneumothorax (A) and after the chest tube placement (B).

a poorly differentiated lung carcinoma that was widely necrotic and infiltrating the chest wall. The results of biopsy on the vertebral bodies, as well as on the hilar and mediastinal nodes, were negative for neoplastic cells, and consequently, the pTNM was T3 NO (stage IIb).

Five days later, the patient complained of dyplopia, headache, and decrease of bilateral sight. He went to the first aid department, where a brain computed tomographic scan was performed, showing a massive hypotensive pneumoencephalus (Figure 1). At chest radiography, a remarkable right hydropneumothorax was present (Figure 2, A). The patient was referred to our department, where a chest tube was positioned on the middle axillary line at the VI space, evacuating about $2000 \mathrm{~mL}$ of sero-hematic pleural fluid and air. We placed the bed of the patient in the Trendelenburg position and the drainage in aspiration.

The chest radiograph after these procedures showed pulmonary re-expansion (Figure 2, B). Contemporarily, we noted the resolution of the neurologic complaints and the improvement of his general condition. Twelve days later, a new brain computed tomographic scan was performed, showing a complete resolution of the intraventricular and extraventricular pneumoencephalus.

Afterward, the chest tube was removed, and the patient's clinical state progressively improved. On the 15 th day, the patient was discharged.

\section{Discussion}

Randomized trials, as well as meta-analysis, show the benefit of neoadjuvant treatments in selected patients with locally advanced stage III non-small cell lung cancer. However, a combined modality treatment can increase morbidity and mortality after surgical intervention in patients with stage III non-small cell lung cancer ${ }^{7}$ because it is associated with more postoperative complications, especially when extended resections have been performed. Up to now, pneumoencephalus after a thoracic operation was never documented. Speculating about its pathogenesis, we can hypothesize that the pneumoencephalus was imputable to a dura mater lesion, determined during the disarticulation of the transverse process of D2, and a hypertensive hydropneumothorax, which complicated the late postoperative course and generated a pressure gradient allowing the air to go inside the liquoral space. The chest tube, which solved the pneumothorax, and the Trendelenburg position of the patient, which allowed the air to go out of the liquoral space, were necessary and sufficient to take care of the pneumoencephalus. The dura mater lesion was small and unknown by the surgeons, who otherwise could appreciate the cerebrospinal fluid leak and attempt to repair or protect it with a pleural-muscle flap or use of fibrin glue. Moreover, if the dura mater lesion had been substantial, the pneumoencephalus could have been of early and not late onset. 
This report, emphasizing a possible complication of en bloc resections involving the vertebral bodies, especially after chemotherapy, radiotherapy, or both, might prompt the thoracic surgeon to evaluate a possible solution of continuity of the dura mater during extended lung resections.

\section{References}

1. Luketich JD, van Raemdonck DE, Ginsberg RJ. Extended resection for higher-stage non-small-cell lung cancer. World J Surg. 1993;17(6):719-28.

2. Pairolero PC. Extended resections for lung cancer. How far is too far? Eur J Cardiothorac Surg. 1999;16(suppl 1):S48-50.

3. Bardet E, Moro-Sibilot D, Le Chevalier T, Massard G, Douillard JY, Theobald S, et al. Standards, options and recommendations for the management of locally advanced non small cell lung carcinoma. Bull Cancer. 2001;88(4):369-87.
4. Van Zandwijk N. Neoadjuvant strategies for non-small cell lung cancer. Lung Cancer. 2001;34(suppl 2):S145-50.

5. Non-Small Cell Lung Cancer Collaborative Group. Chemotherapy in non-small cell lung cancer: a meta-analysis using updated data on individual patients from 52 randomised clinical trials. BMJ. 1995;311: 899-909.

6. Meko J, Rusch VW. Neoadjuvant therapy and surgical resection for locally advanced non-small cell lung cancer. Semin Radiat Oncol. 2000;10(4):324-32.

7. Fowler WC, Langer CJ, Curran WJ, Keller ST. Post-operative complications after combined neo-adjuvant treatment of lung cancer. Ann Thorac Surg. 1993;55:986-9.

8. Bayo Poleo R, Jimeno Torres B, Antona Diaz M, Fernandez de Alarcon L. Traumatic disseminated pneumoencephalus. Rev Clin Esp. 1998; 198(1):45-6.

9. Saxena S, Ambesh SP, Saxena HN, Kumar R. Pneumoencephalus and convulsions after ventriculoscopy: a potentially catastrophic complication. J Neurosurg Anesthesiol. 1999;11(3):200-2.

\title{
Rupture of a chronic expanding hematoma of the thorax into lung parenchyma
}

\author{
Kenichi Okubo, MD, Toshihiro Okamoto, MD, Jun Isobe, MD, and Yoichiro Ueno, MD, Gifu, Japan
}

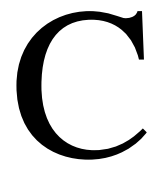

hronic expanding hematoma of the thorax is a rare entity and usually identified with mediastinal compression or chest wall protrusion in patients with a history of thoracotomy, tuberculous pleurisy, or thoracic trauma. We present a patient with chronic expanding hematoma of the thorax who had a massive hemoptysis caused by rupture into lung parenchyma.

\section{Clinical Summary}

A 59-year-old woman with a history of thoracoplasty, which included resection of the 9 th to 11 th ribs for tuberculous empyema 24 years earlier, presented with a massive hemoptysis and dyspnea. She had had a chest wall protrusion pointed out for 4 months. She was brought to our hospital by ambulance, and chest roentgenography showed bilateral lung opacity. The chest roentgenogram 2 months before showed a right intrathoracic mass-like shadow with pleural calcification (Figure 1). Because of the repet-

\footnotetext{
From the Department of General Thoracic Surgery, Gifu National Hospital, Gifu, Japan.

Received for publication Nov 4, 2003; accepted for publication Dec 15, 2003.

Address for reprints: Kenichi Okubo, MD, General Thoracic Surgery, Gifu National Hospital, Japan, 5-1-1 Hinohigashi, Gifu 500-8718, Japan (E-mail: okubo@gifu.hosp.go.jp).

J Thorac Cardiovasc Surg 2004;127:1838-40

$0022-5223 / \$ 30.00$

Copyright $\odot 2004$ by The American Association for Thoracic Surgery

doi:10.1016/j.jtcvs.2003.12.042
}

itive hemoptysis and the progression of cyanosis, emergency tracheal intubation was done to secure the airway. The bleeding was suspected from the right middle or lower lobe, and the right bronchus intermedius was blocked with a balloon within an endotracheal tube (Univent; Fuji System Corp, Tokyo, Japan). Computed tomography showed a heterogenous mass in the right thorax protruding into the chest wall and the right lung (Figure 2). The left lung was also opacified with infiltrate, indicating contralateral spread of the bleeding. Urgent bronchial arteriography was performed; the dilated bronchial artery and intercostal arteries were embolized with platinum coils and gelatin (Spongel; Yomanouchi Co, Tokyo, Japan). Despite the arterial embolization, hemostasis was not obtained immediately, and the balloon was kept inflated until the next day. Six days later, when the left infiltrate improved, the patient underwent a right pneumonectomy through a median sternotomy. Fresh hematoma was identified within the chronic organized hematoma in the thorax and penetrated into the right lung parenchyma. All the hematoma was extirpated along with pneumonectomy. Operating time was 315 minutes, and blood loss was $2077 \mathrm{~mL}$.

Postoperatively, the patient required ventilatory support for respiratory failure. After 6 days of ventilatory support, she was weaned from the respirator. After respiratory rehabilitation, she was discharged from the hospital on postoperative day 43. She has been doing well and has been free from any symptoms of the disease for $3 \frac{1}{2}$ years.

\section{Discussion}

Chronic expanding hematoma of the thorax is a rare entity. Affected patients typically have a history of medical or surgical therapy for tuberculosis. Since Iuchi and associates ${ }^{1}$ reported 5 